\title{
Temozolomide-induced modification of the CXC chemokine network in experimental gliomas
}

\author{
CÉLINE BRUYÈRE $^{1}$, TATJANA MIJATOVIC ${ }^{1}$, CAROLINE LONEZ ${ }^{2}$, SABINE SPIEGL-KREINECKER ${ }^{3}$, \\ WALTER BERGER ${ }^{4}$, RICHARD E. KAST ${ }^{5}$, JEAN-MARIE RUYSSCHAERT ${ }^{2}$, \\ ROBERT KISS $^{1}$ and FLORENCE LEFRANC ${ }^{1,6}$
}

\begin{abstract}
${ }^{1}$ Département de BioAnalyse et de Toxicologie Pharmaceutique, Laboratoire de Toxicologie, Faculté de Pharmacie, Université Libre de Bruxelles (ULB), Brussels; ${ }^{2}$ Laboratoire de Structure et Fonction des Membranes Biologiques, Centre de Biologie Structurale et de Bioinformatique, ULB, Brussels, Belgium; ${ }^{3}$ Department of Neurosurgery, Wagner Jauregg Hospital, Linz; ${ }^{4}$ Department of Medicine I, Institute of Cancer Research, Medical University of Vienna, Vienna, Austria; ${ }^{5}$ Department of Psychiatry, College of Medicine, University of Vermont, Burlington, VT, USA; ${ }^{6}$ Service de Neurochirurgie, Hôpital Erasme, ULB, Brussels, Belgium
\end{abstract}

Received December 2, 2010; Accepted January 17, 2011

DOI: 10.3892/ijo.2011.964

\begin{abstract}
CXCL chemokines display important roles in glioblastoma (GBM) biology, including cell proliferation, death and migration features. While temozolomide (TMZ) represents the standard chemotherapeutic used to treat GBM patients, its role in CXCL networking in GBMs remains unexplored. The effects of short-term and long-term in vitro treatment with temozolomide on CXCL chemokine expression were characterized in human malignant glioma cell lines. U373 and T98G astroglioma and Hs683 oligodendroglioma cells were cultured for months in the presence of increasing concentrations of TMZ (up to $1 \mathrm{mM}$ ), and their whole genome profiles were analyzed along with a complete mapping of all CXCL chemokines and their respective receptor mRNAs. The study was extended to an additional established cell line and four primocultures. The in vitro results were compared with a clinical series of 156 human gliomas and 23 normal brain tissue samples. The expression and secretion of CXCL2, CXCL3 and CXCL8 following different TMZ treatments were determined in Hs683, U373 and T98G glioma cells. The longterm TMZ-treated astroglioma cells, but not the Hs683 oligodendroglioma cells, developed in vivo a certain level of resistance to $\mathrm{TMZ}$, which correlated with the up- regulation of CXCL2, CXCL3 and CXCL8 expression in the U373 and T98G astroglioma cells. The transient down-regulation of CXCL2 in Hs683 glioma cells using siRNA markedly impaired
\end{abstract}

Correspondence to: Dr Robert Kiss, Laboratoire de Toxicologie, Faculté de Pharmacie, Université Libre de Bruxelles (ULB), Campus de la Plaine, CP205/1, Boulevard du Triomphe, 1050 Brussels, Belgium

E-mail: rkiss@ulb.ac.be

Key words: CXC chemokines, glioblastoma, oligodendroglioma, chemoresistance, temozolomide their proliferation rate. In conclusion, $\mathrm{TMZ}$ affects the expression and secretion of CXCL2 (and, to a lesser extent, CXCL3 and CXCL8) in glioma cells, and CXCL2 directly impacts glioma cell biology.

\section{Introduction}

Gliomas are the most common primitive tumors of the brain and, among them, glioblastomas (GBM) have the highest level of malignancy (1-3). GBM patients cannot be currently cured, even following aggressive surgery, radiotherapy and concomitant administration of temozolomide (TMZ) (2-5). Resistance to pro-apoptotic stimuli and, therefore, resistance to conventional chemotherapy and radiotherapy, and the invasion of distant brain parenchyma in a diffuse and extensive manner are prominent features of GBMs, complicating treatment efforts $(5,6)$. TMZ is one of the few current cytotoxic cancer chemotherapeutic agents that can cross the blood-brain barrier and that overcomes the intrinsic resistance of glioma cells to pro-apoptotic stimuli through sustained pro-autophagic stimuli $(7,8)$, ultimately leading to apoptosis (9). TMZ has also demonstrated significant anti-angiogenic effects in experimental gliomas $(10,11)$, and it seems that chemokines in general, and CXC chemokines in particular, play major roles in glial and glioma cell biology, including neoangiogenesis (12). TMZ-induced modifications in glioma CXC chemokine network has not been reported previously, to the best of our knowledge.

Chemokines are low-molecular weight peptides that establish concentration gradients that direct target cell migration $(13,14)$. More than 50 human chemokines and 18 chemokine receptors have been identified to date $(13,14)$ and 16 chemokines belong to the CXC subgroup $(13,14)$. Some CXC receptors bind to more than one chemokine, and some CXC chemokines bind to more than one receptor $(13,14)$. CXCL1 has been shown to mediate the proliferation of glia progenitor cells during neural development and contribute to gliomagenesis (15). CXCR4-mediated signaling can stimulate the proliferation 
of GBM progenitor cells (16). CXCR4 expression and the expression of its ligand, CXCL12, are up-regulated in GBMs $(17,18)$, and they are involved in directing glioma invasion $(17,19)$. The level of CXCL8 (interleukin-8; IL-8) increases as the histological malignancy grade increases in gliomas (12).

The present study focuses on: a) changes in CXCL2, 3 and 8 caused by short- or long-term treatment with TMZ in vitro and b) the identification of CXC chemokines that potentially mediate acquired TMZ resistance in glioma cells. We used three highly malignant human glioma cell lines, two of astroglial origin (U373 and T98G) (20-22) and one of oligodendroglial origin (Hs683) (20-23). The validation of the oligodendroglial origin of the Hs683 model has been demonstrated using multiple assays: Hs683 tumor cells are 1p19q co-deleted (21) and display a high expression level of integrin $\beta 4$ (20) similar to human oligodendroglioma biopsies $(20,24)$; Hs683 cells do not express the human $1 \mathrm{p}$-distal ATAD $3 B$ gene, which is highly expressed in astroglioma cells (25) and Hs683 cells contain only one Notch 2 gene copy per diploid genome, a profile that is similar to oligodendrogliomas (22) in which the loss of the $1 \mathrm{p}$ centromeric marker within intron 12 of the Notch 2 gene is associated with a favorable prognosis in oligodendroglioma patients (26).

We recently showed that long-term in vitro TMZ treatment induces marked amino acid metabolism modifications and an increase in in vivo TMZ sensitivity in Hs683 oligodendroglioma cells (27). In contrast, long-term in vitro TMZ treatment of human U373 and T98G astroglioma cells increases resistance in vivo through up-regulation of GLUT transporter and aldoketo reductase enzyme AKR1C expression (28). The current work thus aims at characterizing CXC chemokine networks in these long-term TMZ-treated Hs683, T98G and U373 glioma cells.

\section{Materials and methods}

\section{Cell lines, media and compounds}

Established cell lines. The human GBM cell lines Hs683 (ATCC code HTB-138), U373 (ATCC code HTB-17), T98G (ATCC code CRL1690) and U87 (ATCC code HTB14) were obtained from the American Type Culture Collection (ATCC; Manassas, VA, USA) and maintained in our laboratory as described previously $(20,21)$.

Primocultures. Four distinct primary GBM cell cultures of astrocytic origin (designated GBM-P5, GBM-P16, GBM-P17 and GBM-P19 in the present study) were established at the Department of Neurosurgery, Wagner Jauregg Hospital, Linz as previously described (29). Briefly, surgical specimens of histo-cytologically confirmed GBM lesions from various sites were blended mechanically and transferred into culture flasks containing growth medium [RPMI-1640, 20\% fetal calf serum (FCS), $1 \%$ glutamine, $1 \%$ penicillin/streptomycin; PAA Laboratories, Linz, Austria]. After passage 3, the cells were cultured in growth medium supplemented with $10 \%$ FCS and $1 \%$ glutamine without antibiotics. Three to five culture flasks were set up from each surgical specimen. Cell cultures from the same patient were then pooled during the first passage. All cell cultures were periodically checked for Mycoplasma contamination (Mycoplasma Stain Kit, Sigma, St. Louis, MO).
Compounds. Temozolomide (TMZ) was obtained from Merck, Sharp and Dohme (MSD; Brussels, Belgium).

Long-term treatment of GBM cell lines with TMZ. Hs683, U373 and T98G cells were treated as described previously $(27,28)$. Briefly, the glioma cells were treated with: a) $0.1 \mu \mathrm{M}$ TMZ twice a week (Monday and Thursday) for 4 weeks (the medium was replaced at each TMZ treatment); b) $1 \mu \mathrm{M} \mathrm{TMZ}$ twice a week for 5 weeks; c) $10 \mu \mathrm{M}$ TMZ twice a week for 12 weeks with a 1-week incubation in the absence of TMZ after each week of TMZ treatment; d) $50 \mu \mathrm{M} \mathrm{TMZ}$ once a week for 3 weeks with a 1-week incubation in the absence of TMZ after every 2 weeks of TMZ treatment; e) $100 \mu \mathrm{M} \mathrm{TMZ}$ twice a week for 8 weeks with a 1 -week incubation in the absence of TMZ after every two weeks of TMZ treatment; $f$ ) $500 \mu \mathrm{M}$ TMZ twice a week for 8 weeks with a 1-week incubation in the absence of TMZ after every 2 weeks of TMZ treatment; g) $1 \mathrm{mM} \mathrm{TMZ} \mathrm{twice} \mathrm{a} \mathrm{week} \mathrm{for} 4$ weeks with a 1-week incubation in the absence of TMZ after every week of TMZ treatment. The cells were analyzed for genomic and proteomic purposes after a 4 -week incubation in the absence of TMZ after the termination of the TMZ treatment described in $(\mathrm{g})$.

Animal models. The in vivo data reported in the current study are from two studies recently published by our group $(27,28)$. We reported the survival curves of TMZ-naïve (TMZ-N phenotype) versus long-term TMZ-treated (TMZ-LTT phenotype) glioma-bearing immunocompromized mice in these two previous studies $(27,28)$. We report in the current study additional in vivo data that have not been published previously.

All mice (6-week-old female nu/nu mice weighing 21-23 g; Janvier, Le Genest-Saint-Isle, France) in a given experiment had GBM TMZ-N (11 mice per group per experimental model) or TMZ-LTT (11 mice per group per experimental model) cells stereotactically implanted into their brain on the same day. The increased survival in these models was assessed using the $\mathrm{T} / \mathrm{C}$ index, which represents the ratio of the median survival time of the treated animal group (T) divided by that of the control group (C) multiplied by 100. A score of 100, therefore, indicates no treatment benefit because the treated and control survival curves were equal.

We also orthotopically grafted Hs683 ( $10^{5}$ cells/mouse), U373 ( $2.5 \times 10^{6}$ cells/mouse), T98G $\left(2.5 \times 10^{6}\right.$ cells/mouse $)$, U87 ( $10^{6}$ cells/mouse), GBM-P5 ( $2 \times 10^{6}$ cells/mouse), GBM-P16 ( $2 \times 10^{6}$ cells/mouse), GBM-P17 ( $2 \times 10^{6}$ cells/mouse) or GBM-P19 ( $2 \times 10^{6}$ cells/mouse) cells intogroups of $11 \mathrm{immunocompromised}$ mice to determine the rate with which these GBM models killed the mice.

All of the in vivo experiments described in the present study were performed with the approval of the Animal Ethics Committee of the Federal Department of Health, Nutritional Safety and the Environment (Belgium; Authorization \#LA1230509).

CXC chemokine and CXC chemokine receptor expression in primary gliomas. The expression of 14 CXC chemokines and 6 CXC chemokine receptors was analyzed in a series of 179 human brain samples, including 23 normal brain tissue specimens, 10 grade II astrocytomas, 19 grade III astrocytomas, 
Table I. Sequences of the primers used in the current study.

\begin{tabular}{|c|c|c|c|c|}
\hline $\begin{array}{l}\text { Targets } \\
\text { (synonym names) }\end{array}$ & Locus & Forward sequences & Reverse sequences & $\begin{array}{l}\text { Annealing } \\
\text { temperature }\end{array}$ \\
\hline CXCL1 (GRO- $\alpha)$ & NM001511 & agggtatgattaactctacctg & ccattaaacaaggcagtatgc & 57.3 \\
\hline CXCL2 (GRO- $\beta$ ) & NM002089 & gtcaaacccaagttagttca & cagtatgccttacaagaaagac & 57 \\
\hline CXCL3 (GRO- $\gamma)$ & NM002090 & agcttatcagcgtatcattgac & ccctaacagtgatccactaa & 58.2 \\
\hline CXCL4 (PF4) & NM002619 & ccagcgctgaagctggaagaagatgg & cttgtacagcggggettgcaggtcc & 60 \\
\hline CXCL5 (ENA-78) & NM002994 & agagtagaacctgggttaga & cctacaagccttttcacaag & 58 \\
\hline CXCL6 (GCP-2) & NM002993 & ttgaaccetttggcaattg & gggtaaagagtaacatattccc & 57.5 \\
\hline CXCL7 (NAP-2) & NM002704 & cttgtaggcagcaactca & gcatacaagtcactgtctaga & 58 \\
\hline CXCL8 (IL8) & NM000584 & tgggtgcagagggttgtg & cagactagggttgccagattta & 60 \\
\hline CXCL9 (MIG) & NM002416 & gctttctaagatctaacaagatagc & ggaactagggagtttcatga & 58.2 \\
\hline CXCL10 (IP-10) & NM001565 & atgaatcaaactgcgattctgatt & ttaaggagatcttttagacatttc & 58 \\
\hline CXCL11 (I-TAC) & NM005409 & ggttaccatcggagtttaca & ccctacatattgatgtgctacatg & 58.8 \\
\hline CXCL12 (SDF-1 $\alpha / \beta)$ & NM199168 & atgaacgccaaggtcgtggtc & cttgtttaaagctttctccaggtact & 60 \\
\hline CXCL13 (BCA-1) & NM006419 & ccctagacgcttcattga & ctcatgccttatttgtatggg & 60 \\
\hline CXCL14 (BRAK) & NM004887 & aagcttccgcttagaggt & cctaaggtttttgctgacagt & 60 \\
\hline CXCL16 (SCYB16) & NM001100812 & ctggactcagccaggcaatgg & tgagtggactgcaaggtgga & 55 \\
\hline CXCR1 (IL8RA) & NM000634 & ggctgctggggactgtctatgaat & gcccggecgatgttgttg & 57 \\
\hline CXCR2 (IL8RB) & NM001557 & gtaattacagttacagctctaccc & gctaacattggatgagtagacg & 60 \\
\hline CXCR3 (IP10-R) & NM001504 & tggacatcctcatggacctg & gaagtcagactgtgggcgaa & 62 \\
\hline CXCR4 (CD184) & NM001008540 & atcttcetgeccaccatctactccatcatc & atccagacgccaacatagaccaccttttca & 57 \\
\hline CXCR5 (BLR1) & NM001716 & agctatagacccgaggaa & agcttgcgaggagatact & 57.5 \\
\hline CXCR6 (BONZO) & NM006564 & gtcatatccatcttctaccataagt & aattgcctcgtcatggtaa & 58.8 \\
\hline CXCR7 (CMKOR1) & NM020311 & tcaatcgcaactacaggtac & atcaagacccgaagctac & 57 \\
\hline KSHV (MLF1IP) & NM024629 & tgttaccttctgaaactgtacc & ggtgtaaattcaggagaaatcg & 60 \\
\hline Duffy (DARC) & NM002036 & cttcctatggtgtgaatgattc & aagagaggtctgaaaagcat & 57.5 \\
\hline
\end{tabular}

77 GBMs (grade IV), 38 grade II oligodendrogliomas and 12 grade III oligodendrogliomas. The microarray data were generated by the Henry Ford Hospital (Detroit, MI) using an Affymetrix Array Series GSE4290 (http://www.ncbi.nlm.nih. gov/geo/query/acc.cgi?acc=GSE4290).

\section{RT-PCR and quantitative RT-PCR}

Total RNA extraction. Total RNA was extracted using the TRIzol isolation reagent (Life Technologies, Merelbeke, Belgium) according to the manufacturer's instructions. The extracted RNA was treated with DNase I (Life Technologies) to eliminate any residual genomic DNA. The quality and integrity of the extracted RNA was assessed using both a BioAnalyzer 2100 (Agilent, Toulouse, France) and gel electrophoresis. The primers used for PCR along with the experimental conditions used for each primer are listed in Table I.

Standard and quantitative RT-PCR analyses. Reverse transcription (RT) reactions were carried out in a thermal cycler (Thermocycler, Westburg, Leusden, The Netherlands). The resulting cDNAs were purified using the High Pure PCR Product Purification Kit (Roche Diagnostics, Mannheim, Germany) following the manufacturer's protocol. The integrity of the cDNA was confirmed based on $\beta$-actin gene expression following a 25 -cycle standard PCR in a total volume of $50 \mu \mathrm{l}$ with 20 ng of loaded cDNA. All standard PCR reactions were carried out in a thermal cycler (Thermocycler). The cycling parameters were as follows: pre-denaturation for $10 \mathrm{~min}$ at $95^{\circ} \mathrm{C}$; denaturation for $30 \mathrm{sec}$ at $95^{\circ} \mathrm{C}$; annealing for $45 \mathrm{sec}$ at the temperature indicated in Table I $\left(62^{\circ} \mathrm{C}\right.$ for $\beta$-actin); elongation for $45 \mathrm{sec}$ or $1 \mathrm{~min}$ at $72^{\circ} \mathrm{C}$; and a final elongation for $10 \mathrm{~min}$ at $72^{\circ} \mathrm{C}$. The reactions were incubated for 35 cycles with the exception of the $\beta$-actin amplification, which was only incubated for 25 cycles. All of the PCR analyses were performed using $20 \mathrm{ng}$ of the purified cDNA. The products were resolved using gel electrophoresis in $1 \%$ agarose TBE gels and visualized with SYBR safe (Invitrogen) staining under UV light.

Quantitative RT-PCR (qRT-PCR) reactions were performed using $20 \mathrm{ng}$ of purified cDNA in a LightCycler Thermocycler (Roche Diagnostics, Vilvoorde, Belgium) using LC-FastStart DNA Master SYBR Green 1 (Roche Diagnostics, Vilvoorde). After amplification, data analysis was performed using the 'Fit points' algorithm of the LightCycler quantification software. A standard curve established through serial dilution $\left(5 \times 10^{2}-\right.$ $10^{8}$ copies $/ \mu 1$ ) of the PCR products generated with specific primers enabled quantification of the cDNA present in the samples.

The primers used were synthesized by Invitrogen and selected using the HYBSIMULATOR software (Advanced 
Gene Computing Technology, Irvine, USA). The primers used for CXCL and CXCR evaluation are listed in Table I.

Genomic analysis. Whole genome analyses were performed on TMZ-N and TMZ-LTT GBM cells at the VIB MicroArray Facility (UZ Gasthuisberg, Catholic University of Leuven, Leuven, Belgium) using the Affymetrix Human Genome U133 set Plus 2.0 (High Wycombe, UK). The data analyses were carried out as described previously $(27,28)$.

Enzyme-linked immunosorbent assays (ELISA). Three different ELISA kits were used in this study for the quantification of human CXCL2 (GRO- $\beta$ ELISA Construction Kit, Antigenix America, NY, USA), human CXCL3 (GRO- $\gamma$ ELISA Construction Kit, Antigenix America) and CXCL8 (IL-8; Quantikine ELISA R\&D Systems, Abingdon, UK) in accordance with the manufacturer's instructions. For the CXCL2 and CXCL3 ELISA Construction Kits, the plates were coated with $1 \mu \mathrm{g} / \mathrm{ml}$ capture antibody, while the detector antibody was used at $0.25 \mu \mathrm{g} / \mathrm{ml}$. Cell culture supernatants were collected after different treatments and time periods (as indicated in the figure legends), with multiple aliquots taken and stored at $-20^{\circ} \mathrm{C}$ until analysis. The results from the ELISAs were assessed as absorbance values, and the concentration of the three specific chemokines were expressed as $\mathrm{pg} / \mathrm{ml}$.

Immunofluorescence. Cells were cultured on coverslips and fixed with $4 \%$ formaldehyde in PBS for $20 \mathrm{~min}$ at $4^{\circ} \mathrm{C}$. The fixed cells were permeabilized using $0.2 \%$ (v/v) Triton X-100 and $10 \%(\mathrm{w} / \mathrm{v})$ bovine serum albumin for $20 \mathrm{~min}$. The cells were washed twice with PBS and blocked in PBS containing $0.1 \%$ bovine serum albumin for $1 \mathrm{~h}$ at room temperature. The cells were then stained for $1 \mathrm{~h}$ at room temperature with a polyclonal antibody against CXCL2 (Santa Cruz Biotechnology). Antigens were detected using an anti-goat secondary antibody conjugated to Alexa Fluor 594 (Invitrogen, Merelbeke, Belgium). The coverslips were mounted on microscope slides with $10 \mu 1$ Moviol agent (Calbiochem, VWR, Heverlee, Belgium). Images were captured using a 40x immersion objective (Zeiss observer. Z1, Zeiss, Oberkochen, Germany) and an Axiocam HRm Zeiss camera (Zeiss) controlled by software. The images were converted to stacks and navigated using Axiovison Rel 4.6 software. The images of CXCL2 staining were analyzed with the same exposure for all treated and untreated samples. Between 40 and 80 cells were analyzed for each experimental condition, and representative data are shown.

Transient knock-down of CXCL2 in Hs683 cells using a CXCL2specific siRNA. Three different CXCL2-specific siRNAs were designed by Eurogentec (Eurogentec, Seraing, Belgium). The sequence of the CXCL2 siRNA (Eurogentec) used in the current work was $5^{\prime}$-gcaucgcccaugguuaaga-3' for the sense sequence and 5'-ucuuaaccaugggcgaugc-3' for the antisense sequence. A siRNA negative control (Eurogentec) was used as a processing control. The antisense and sense strands of the siRNA were annealed by the manufacturer in $50 \mathrm{mM}$ Tris, $\mathrm{pH} 7.5-8.0$ and $100 \mathrm{nM} \mathrm{NaCl}$ in diethylpyrocarbonate-treated water. The final concentration of the siRNA duplex was $100 \mu \mathrm{M}$.

Hs683 cells were either left untreated (wild-type; wt) or were transfected with DiC14-amidine/siRNA lipoplexes. The
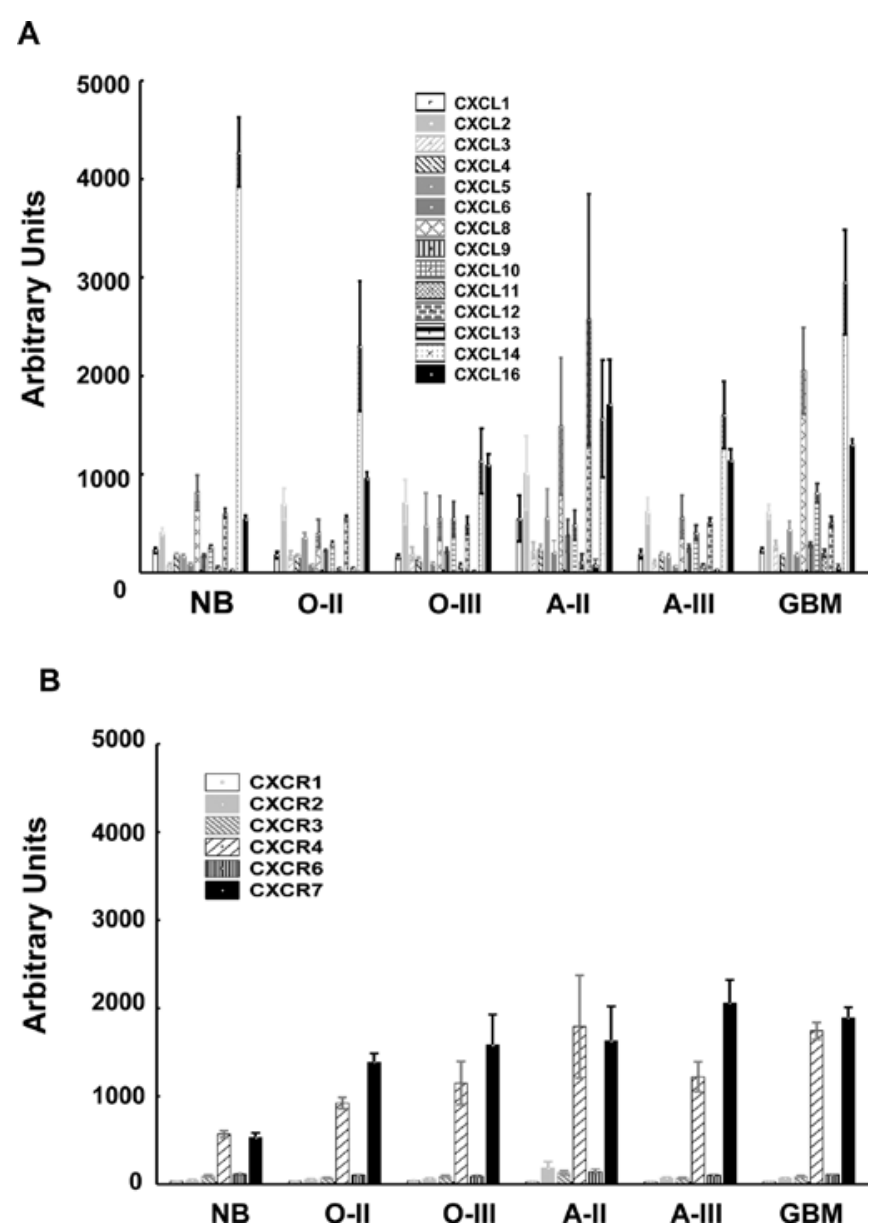

Figure 1. Determination of CXC chemokine (A) and CXC chemokine receptor (B) genomic expression in 23 normal brain samples (NB) and 159 gliomas [O-II = oligodendroglioma grade II $(\mathrm{n}=38)$; O-III = oligodendroglioma grade III $(\mathrm{n}=12) ; \mathrm{A}-\mathrm{II}=$ astrocytoma grade II $(\mathrm{n}=10) ; \mathrm{A}-\mathrm{III}=$ astrocytoma grade III $(\mathrm{n}=19)$ and $\mathrm{GBM}=$ glioblastoma $(\mathrm{n}=77$; grade IV) $]$. The data were retrieved from microarray experiment performed at the Henry Ford Hospital (GSE4290) as described in the Materials and methods. The data are reported as means \pm SEM.

liposome preparation is described below. DiC14-amidine (3-tetradecylamino-N-tert-butyl-N-tetradecylpropionamidine) was synthesized (30) and used to generate liposomes as previously described (31). Briefly, after dissolving the diC14amidine in chloroform, the solvent was evaporated under a $\mathrm{N}_{2}$ stream. The resulting lipid film was further dried under vacuum overnight. The lipid film was hydrated in HBS-10 buffer (10 mM HEPES, $150 \mathrm{mM} \mathrm{NaCl}, \mathrm{pH} 7.3)$ that had been prewarmed to $55^{\circ} \mathrm{C}$ to reach a concentration of $1 \mathrm{mg} / \mathrm{ml}$ and vortexed for $1 \mathrm{~min}$. The liposomes were then extruded seven times through a $0.4-\mu \mathrm{m}$ polycarbonate filter (GE Osmonics, Herentals, Belgium) at $55^{\circ} \mathrm{C}$ and stored at $4^{\circ} \mathrm{C}$ in a $4-\mathrm{ml}$ polystyrene tube (Falcon, VWR, Heverlee, Belgium). For all experiments, the liposomes were incubated at $55^{\circ} \mathrm{C}$ for $10 \mathrm{~min}$ before use.

To generate the DiC14-amidine/siRNA complexes, a volume of $0.4 \mu \mathrm{M}$ siRNA (usually $200 \mu \mathrm{l}$ ) was added to $20 \mu \mathrm{g}$ diC14-amidine liposomes in an equal volume of RPMI (Invitrogen) while gently shaking the tube. The liposome/siRNA mixture was allowed to stand for $20 \mathrm{~min}$ at room temperature before use. Under these conditions, the complex has a cationic 
Table II. Qualitative determination of the mRNA levels of CXCL chemokines and CXCL receptors (CXCL-R) in eight human glioma cell lines.

\begin{tabular}{|c|c|c|c|c|c|c|c|c|c|}
\hline CXCL & CXCL-R & GBM-P5 & GBM-P16 & GBM-P17 & GBM-P19 & Hs683 & T98G & U87 & U373 \\
\hline \multirow[t]{4}{*}{ CXCL1 } & & ++ & ++ & - & - & ++ & - & ++ & - \\
\hline & $\mathrm{CXCR} 2^{\mathrm{A}, \mathrm{C}}$ & + & - & + & + & + & - & + & - \\
\hline & $\mathrm{KSHV}^{\mathrm{H}}$ & + & - & + & + & + & + & + & + \\
\hline & DUFFY & - & + & - & - & + & - & - & - \\
\hline $\mathrm{CXCL}^{\mathrm{A}}$ & & ++ & + & - & ++ & ++ & ++ & ++ & ++ \\
\hline CXCL3 & & + & + & - & + & ++ & + & + & + \\
\hline CXCL4 & & - & - & - & - & - & - & - & - \\
\hline CXCL5 $^{\text {B }}$ & & - & ++ & - & + & ++ & + & ++ & - \\
\hline \multirow[t]{2}{*}{ CXCL6 $^{\mathrm{C}}$} & & + & - & - & - & - & - & - & - \\
\hline & $\mathrm{CXCR} 1^{\mathrm{E}}$ & - & - & - & - & ++ & - & - & - \\
\hline $\mathrm{CXCL7}^{\mathrm{D}}$ & & - & - & - & - & ++ & - & ++ & - \\
\hline CXCL8 ${ }^{\mathrm{E}}$ & & ++ & ++ & ++ & ++ & ++ & ++ & ++ & ++ \\
\hline \multirow{2}{*}{ CXCL9 } & & - & - & - & - & - & - & - & - \\
\hline & $\mathrm{CXCR}^{\mathrm{F}, \mathrm{G}}$ & - & - & - & - & + & - & - & - \\
\hline CXCL10 & & - & + & - & - & + & - & + & - \\
\hline \multirow[t]{2}{*}{ CXCL11 } & & - & ++ & + & - & + & - & + & - \\
\hline & CXCR7 & - & +++ & - & + & + & + & + & ++ \\
\hline \multirow[t]{2}{*}{$\mathrm{CXCL} 12^{\mathrm{H}}$} & & & + & + & + & + & + & ++ & + \\
\hline & CXCR4 & ++ & ++ & ++ & + & ++ & - & - & ++ \\
\hline \multirow[t]{2}{*}{ CXCL13 } & & - & - & - & - & - & - & - & - \\
\hline & CXCR5 & - & - & - & - & - & - & - & - \\
\hline CXCL14 & & - & - & + & - & - & ++ & + & + \\
\hline \multirow[t]{2}{*}{ CXCL16 } & & ++ & + & - & ++ & ++ & ++ & - & ++ \\
\hline & CXCR6 & - & - & + & - & - & - & + & - \\
\hline
\end{tabular}

-, negative; +, weakly positive; ++, positive; PCR/35 cycles. The superscript letters represent additional couples of ligand/receptors.

lipid:siRNA ratio of 7.5:1 (w:w), and the charge ratio was calculated to be 4.54 positive charges for every negative charge. The liposome/siRNA mixture was diluted in RPMI (to a concentration of $0.032 \mu \mathrm{M}$ siRNA) and added to Hs683 glioma cells for $2 \mathrm{~h}$. On day 2 , each group of cells was pooled and re-plated for subsequent experiments. On days 5, 7, 9 and 12 , the glioma cells were either scraped into cold PBS (for RNA extraction) or lysed directly in Cellytic (Sigma, Bornem, Belgium). The efficiency of the CXCL2-specific siRNA was evaluated using immunofluorescence and RT-PCR.

Computer-assisted, phase-contrast videomicroscopy. The effects of the CXCL2-specific siRNA (versus control siRNA) on Hs683 viability, growth, division and migration were characterized in vitro using computer-assisted, phase-contrast videomicroscopy as described previously $(32,33)$. The cells were monitored for $168 \mathrm{~h}$, and one image was taken every $4 \mathrm{~min}$.

For each condition (control or treated), cell growth was evaluated using the ratio of the number of cells counted in the last and first frames of the image sequences. All cell counts were performed in triplicate using an interactive computer tool (33).
Statistical analyses. Survival time analyses were carried out by means of Kaplan-Meier curves that were compared with the log-rank test. Statistical comparisons between groups were established by carrying out the nonparametric Mann-Whitney test. The statistical analyses were performed using Statistica software (Statsoft, Tulsa, USA).

\section{Results}

Characterization of the CXCL/CXCL receptor expression pattern in normal brain tissue and gliomas. Fig. 1A provides an overview of the mRNA expression level of fourteen CXC chemokines in normal brain and glioma tissue, while Fig. 1B provides an overview of six CXC receptors. These data were obtained using a microarray database generated by the Henry Ford Hospital (Detroit, MI; see Materials and methods). As seen in Fig. 1A, CXCL2 mRNA was present in all groups analyzed, and the mRNA level of CXCL2 and CXCL8 was similar in all groups with the exception of GBMs, where the CXCL8 mRNA level was greater than the CXCL2 mRNA level. The mRNA level of CXCL2 and CXCL12 was similar in all groups (Fig. 1A). The data in Fig. 1B suggest a direct role for CXCR4 and CXCR7 in gliomagenesis; at least one of 
A

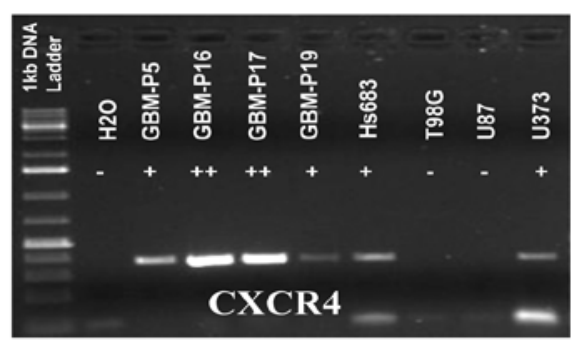

B

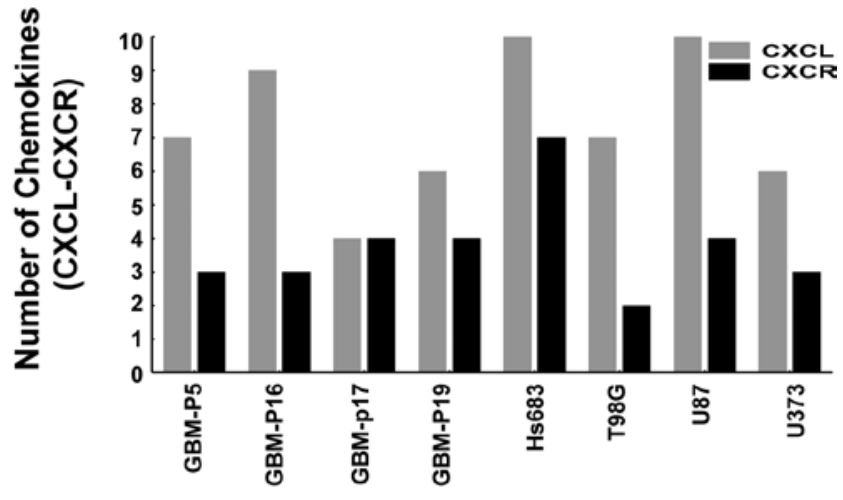

C

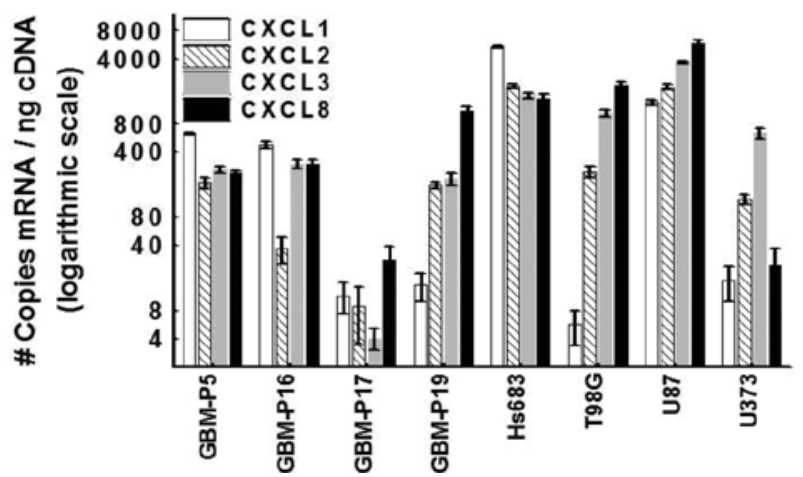

D

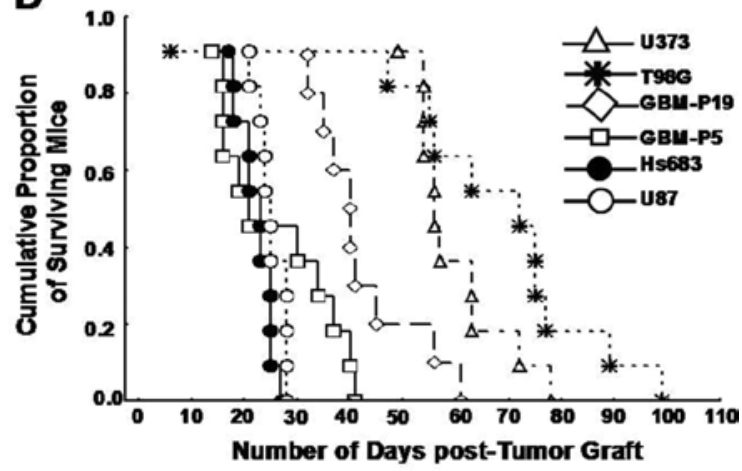

Figure 2. (A), Experimental example of CXCL/CXCR detection using standard RT-PCR technique: CXCR4 expression in the eight GBM cell lines. Conventional RT-PCR was used to determine the expression of each CXCL and CXCL receptor as '-' (absence of mRNA expression), '+' (expression) or '++' (marked expression); complete results are presented in Table II. (B), The total number of CXCL and CXCL receptors in the eight GBM cell lines. (C), Quantitative determination of CXCL1, CXCL2, CXCL3 and CXCL8 mRNA expression in four GBM primocultures (GBM-P5, GBM-P16, GBM-P17 and GBM-19) and four established glioma cell lines (Hs-683, T98G, U87 and U373) using qRT-PCR. Three samples were analyzed per specimen, and the data are reported as means \pm SEM. (D), Survival analysis of immunocompromised mice (11 mice per experimental group) orthotopically implanted with $\mathrm{Hs} 683$ ( $10^{5}$ cells/mouse), U373 ( $2.5 \times 10^{6}$ cells/mouse), T98G ( $2.5 \times 10^{6}$ cells/mouse), U87 ( $10^{6}$ cells/mouse), GBM-P5 ( $2 \times 10^{6}$ cells/mouse), GBM-P16 ( $2 \times 10^{6}$ cells/mouse), GBM-P17

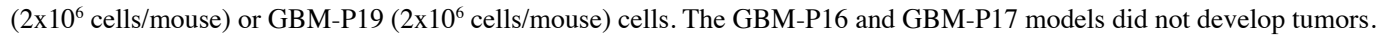

these two receptors was present in each of the eight GBM models examined (Table II).

Determination of CXC chemokine (CXCL) and CXCL chemokine receptor expression in primary GBM samples, GBM primocultures and established cell lines. A complete mapping of the CXCL and CXCL receptor mRNA expression patterns was performed in eight GBM cultures, including four primocultures and four established cell lines. We first used conventional RT-PCR to label the expression of each CXCL and CXCL receptor as '-' (absence of mRNA expression), '+' (expression) or '++' (marked expression), as illustrated in Fig. 2A and detailed in Table II. We did not examine CXCL15, which is specific to rodents (13). As seen in Fig. 2B, a number of CXCLs and CXCL receptors were expressed (denoted as + or ++ in Table II) in the eight glioma cell lines examined. Altogether, 8/8 GBM cell lines expressed CXCL8 and CXCL12, and $7 / 8$ cell lines expressed CXCL2 and CXCL3. We thus used quantitative RT-PCR to determine the mRNA level of CXCL1, CXCL2, CXCL3 and CXCL8 (but not CXCL12, the expression of which is largely described in the literature) in the eight GBM models (Fig. 2C). Except for the GBM-P17 primoculture, which displayed very low mRNA expression for
CXCL1, CXCL2, CXCL3 and CXCL8, the remaining seven GBM cell lines all displayed a high to very high amount of mRNA for these four CXCL chemokines.

We orthotopically grafted the eight GBM cell lines into the brains of immunocompromised mice in order to investigate whether the differences in the CXCL/CXCL receptor pattern of expression translated into different patterns of biological aggressiveness (Fig. 2D). The results revealed that it is not the absolute number of different CXCLs and CXCL receptors present in a given GBM cell line that confers its biological aggressiveness but rather a minimal CXCL/CXCL receptor chemokine network. For example, T98G, which is tumorigenic (Fig. 2D), expressed fewer CXCLs and CXCL receptors (a total of nine; Fig. 2B) than GBM-P16 (a total of twelve; Fig. 2B), which is not tumorigenic (Fig. 2D). In fact, as seen in Table II and Fig. 2D, the four models that aggressively developed in vivo and had median survival times less than 40 days (Hs683, U87, GBM-P5 and GBM-P19) significantly expressed CXCL2/ CXCL2 receptors, CXCL3/CXCL3 receptors, CXCL8/CXCL8 receptors and CXCL12/CXCL12 receptors. The two models that developed less aggressively and had median survival times higher than 40 days (U373 and T98G; Fig. 2D) did not express CXCL2/CXCL2 receptors and CXCL3/CXCL3 receptors 
(Table II). While conventional PCR analyses detected CXCL2 and CXCL3 mRNAs in the non-tumorigenic GBM-P16 model, these analyses failed to detect CXCL2 and CXCL3 mRNAs in the second non-tumorigenic model examined (GBM-P17; Table II). As seen in Fig. 2C, the GBM-P17 model lacked or only minimally expressed mRNAs for these four CXCLs (including CXCL2), and the GBM-P16 model displayed weaker CXCL2 mRNA expression compared to the remaining six GBM models that were tumorigenic (Fig. 2C and D).

A minimum level of CXCL1 mRNA expression (Fig. 2C) did not seem to be mandatory for human GBM cell lines to be tumorigenic in immunocompromised mice, as T98G was tumorigenic (Fig. 2D) but lacked CXCL1 mRNA (Table II and Fig. 2C).

Taken together, these data suggest that all of the tested human GBM cell lines express the CXCL8/CXCL8 receptors and the CXCL12/CXCL12 receptors at the mRNA level (Table II) and that a minimum level of CXCL2 and CXCL3 expression (Fig. 2C) must be reached in these GBM cell lines to confer tumorigenicity in vivo following an orthotopic graft into immunocompromised mice (Fig. 2D).

In vitro long-term treatment of human GBM cells with TMZ decreases CXCL2 and CXCL3 secretion. As seen in Fig. 3, long-term (five consecutive days; black bars) in vitro treatment with TMZ decreased CXCL2 secretion in Hs683, T98G and U373 cells, while a single (one day; gray bars) in vitro treatment with TMZ did not. Long-term in vitro treatments with TMZ decreased the amount of secreted CXCL3 in T98G cells but seemed not in U373 and Hs683 cells (Fig. 3). CXCL8 was secreted at very low levels in these three glioma cell lines (Fig. 3).

Characterization of in vivo TMZ sensitivity of long-term $T M Z$-treated and untreated GBM cell lines. In vitro exposure of Hs683 glioma cells for months to increasing concentrations of TMZ rendered them extremely sensitive to TMZ treatment in vivo [(27); Table III]. Indeed, TMZ treatment increased the survival of TMZ-LTT Hs683 glioma-bearing mice by $336 \%$ when compared to the survival of TMZ-treated TMZ-N Hs683 glioma-bearing mice $(\mathrm{T} / \mathrm{C}=124 \%$; Table III). Whole genome and proteomic analyses revealed that the increased TMZ sensitivity of Hs683 oligodendroglioma cells previously treated for long periods of time with TMZ can be partially explained by a TMZ-induced p38-dependant dormancy state, which resulted in changes in the balance of amino acid metabolism, in a growth delay and in a decrease in Hs683 oligodendroglioma invasiveness (27). Therefore, long-term TMZ treatment seems beneficial in this Hs683 oligodendroglioma model, which did not appear able to develop resistance to TMZ (27). This in vivo increase in the TMZ sensitivity of TMZ-LTT Hs683 gliomas was paralleled by in vitro decreases in both the CXCL2 mRNA and protein level (Fig. 4) and the CXCL2 secretion level (Fig. 3).

In sharp contrast to the Hs683 model, which has an oligodendroglial origin (20-22), the TMZ-LTT U373 and T98G glioma models have an astrocytic origin (20-22) and developed in vivo certain levels of resistance to TMZ [(28); Table III] paralleled by an increase in CXCL2 mRNA and protein
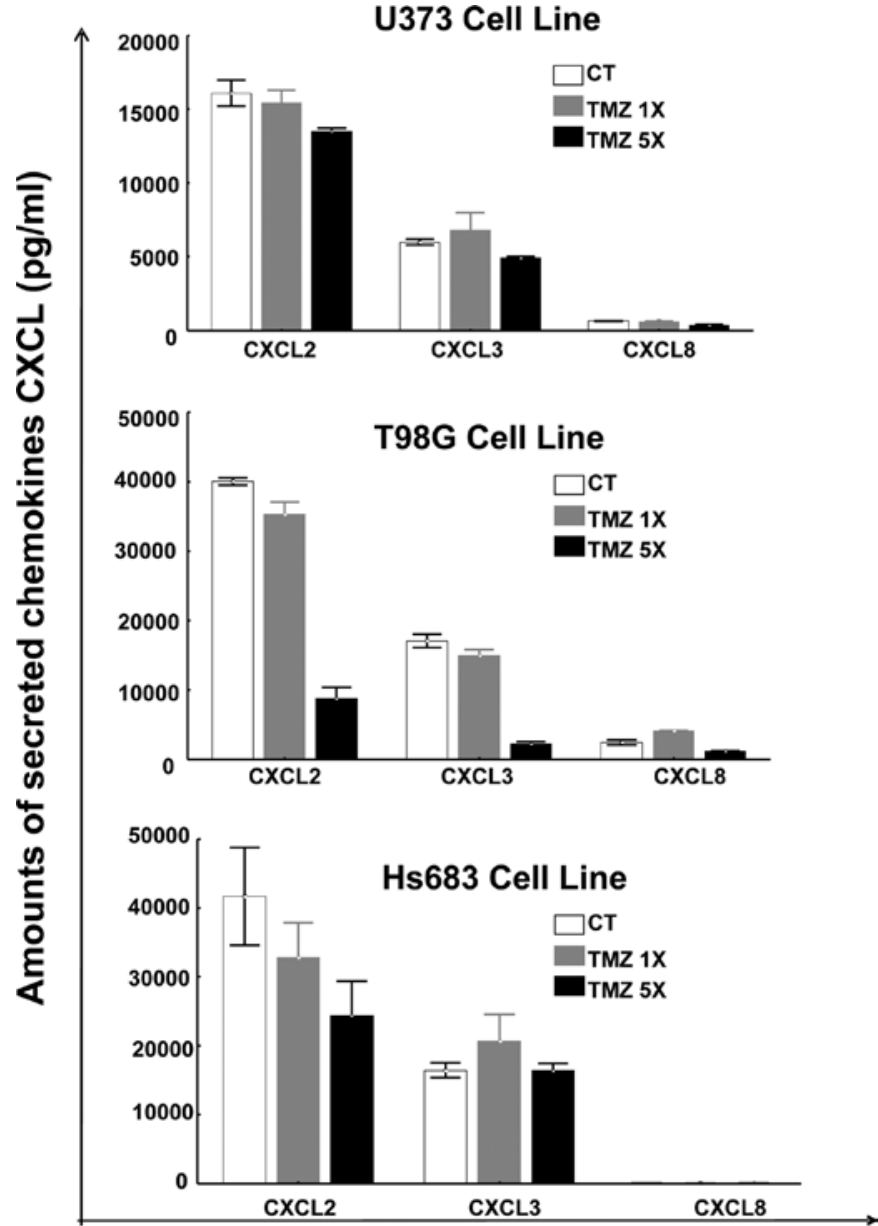

Chemokines CXCL

Figure 3. Characterization of the influence of temozolomide on CXCL2, CXCL3 and CXCL8 chemokine secretion (assayed using ELISA) by Hs683, T98G and U373 cells. The cells were either left untreated (control, CT; open bars), treated once with $100 \mu \mathrm{M}$ temozolomide (gray bars) or treated five times a week with $100 \mu \mathrm{M}$ temozolomide (black bars; $8 \mathrm{~h}$ of TMZ treatment each day with replacement of fresh medium containing TMZ each day). CXCL secretion was measured $24 \mathrm{~h}$ after the last TMZ treatment. The data are presented as means \pm SEM calculated from triplicates.

expression (Fig. 4). The long-term in vitro TMZ treatment of naïve (i.e., cells that have never been treated with TMZ) U373 and T98G cells decreased CXCL2 secretion (Fig. 3).

As seen in Table III, the 'wild-type' (TMZ-N) T98G GBM xenografts displayed greater sensitivity to $\mathrm{TMZ}$ ( $\mathrm{T} / \mathrm{C}>450 \%)$ than the (TMZ-N) U373 GBM xenografts (T/C >247\%). The possibility therefore remains that longer periods ( 2 or 3 weeks) of in vitro TMZ treatment could decrease CXCL2, CXCL3 and CXCL8 secretion levels by GBM cells in a more marked manner than what was observed here with a 1-week TMZ treatment (Fig. 3). It is important to note, however, that very long periods (months) of in vitro TMZ treatment can result in an increase in CXCL2, CXCL3 or CXCL8 expression in glioma cells (Fig. 4).

Effect of the transient knock-down of CXCL2 expression on the in vitro biological behavior of $H$ s 683 cells. Taken together, the data from the previous sections suggest that CXCL2 seems to affect, in one way or another, the biological aggressiveness of GBM cells. Therefore, we characterized the effect of transient 
Table III. Characterization of in vivo TMZ sensitivity of human glioma models that have been first treated for long periods of time in vitro with TMZ.

\begin{tabular}{|c|c|c|c|c|c|c|c|}
\hline $\begin{array}{l}\text { GBM } \\
\text { model }\end{array}$ & $\begin{array}{c}\text { GBM } \\
\text { cell type }\end{array}$ & $\begin{array}{l}\text { Experimental } \\
\text { condition }^{\mathrm{b}}\end{array}$ & $\begin{array}{l}\text { Median } \\
\text { day of } \\
\text { death }^{c}\end{array}$ & $\begin{array}{l}\text { Day of first/ } \\
\text { last mouse death } \\
(\mathrm{n}=11 \text { mice })\end{array}$ & $\mathrm{T} / \mathrm{C}(\%)^{\mathrm{d}}$ & $\begin{array}{c}\text { CT } \\
\text { TMZ-LTT/ } \\
\text { CT TMZ-N }\end{array}$ & $\begin{array}{c}\text { TMZ-LTT/ } \\
\text { TMZ-N }^{\mathrm{e}}\end{array}$ \\
\hline \multirow[t]{4}{*}{ U373 } & TMZ-N & CT & 116 & $78 / 156$ & $>247(\mathrm{p}<0.01)$ & & \\
\hline & & TMZ-treated & $>287^{\mathrm{f}}$ & $100 / 8$ survivors at day 287 & & $44(\mathrm{p}<0.001)$ & $<71(\mathrm{~ns})$ \\
\hline & TMZ-LTT $^{\mathrm{a}}$ & CT & 51 & $42 / 58$ & $398(\mathrm{p}<0.001)$ & & \\
\hline & & TMZ-treated & 203 & $112 / 3$ survivors at day 287 & & & \\
\hline \multirow[t]{4}{*}{ T98G } & TMZ-N & $\mathrm{CT}$ & 62 & $39 / 92$ & $>450(\mathrm{p}<0.001)$ & & \\
\hline & & TMZ-treated & $>279$ & $39 / 8$ survivors at day 284 & & $100(\mathrm{~ns})^{\mathrm{g}}$ & $<67(\mathrm{p}<0.05)$ \\
\hline & TMZ-LTT & CT & 62 & $48 / 83$ & $300(\mathrm{p}<0.001)$ & & \\
\hline & & TMZ-treated & 186 & $76 / 2$ survivors at day 284 & & & \\
\hline \multirow[t]{4}{*}{ Hs683 } & TMZ-N & CT & 21 & $19 / 25$ & $119(\mathrm{p}<0.05)$ & $124(\mathrm{p}<0.01)$ & $336(\mathrm{p}<0.001)$ \\
\hline & & TMZ-treated & 25 & $21 / 27$ & & & \\
\hline & TMZ-LTT & $\mathrm{CT}$ & 26 & $19 / 42$ & $323(\mathrm{p}<0.001)$ & & \\
\hline & & TMZ-treated & 84 & $40 / 145$ & & & \\
\hline
\end{tabular}

The in vivo data reported in the table have been published in terms of survival curves in refs. 27 and 28 . We report in the table additional in vivo data from these two previous studies. ${ }^{a} \mathrm{U} 373$, T98G and Hs683 glioma cells were cultured in vitro for months in the presence of TMZ with concentrations up to $1 \mathrm{mM}$ (Materials and methods). Control glioma cells that were not cultured in presence of TMZ are denoted 'TMZ-naïve' (TMZ-N), while long-term TMZ-treated GBM cells are denoted 'TMZ-LTT'. 'TMZ treatment consisted of three i.v. administrations of $40 \mathrm{mg} / \mathrm{kg}$ TMZ per week for 3 consecutive weeks. The TMZ treatments were started on the fifth day post-tumor implantation for the Hs683 model and on the fourteenth day post-tumor implantation for the U373 and T98G models. ${ }^{\circ}$ There were 11 mice per experimental group; the median death corresponds to the death of the sixth mouse in each group measured in post-tumor implantation days. ${ }^{\mathrm{d}}$ The definition of $\mathrm{T} / \mathrm{C}$ is provided in the

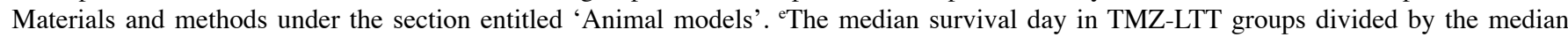

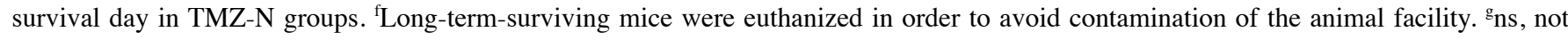
significant $(\mathrm{p}>0.05)$.

CXCL2 silencing on the growth characteristics of Hs683 cells (Fig. 5). Fig. 5A illustrates the CXCL2 silencing efficiency of the three CXCL2-specific siRNAs we designed in our study. As detected using RT-PCR in the U373 cell line (Fig. 5A) and in the Hs683 and T98G cell lines (data not shown), the best silencing effects were obtained with the CXCL2-specific siCXCL2-1 siRNA. The efficiency of this CXCL2-specific siRNA was then validated at the protein level in Hs683 cells (Fig. 5B).

We used computer-assisted, phase-contrast microscopy (quantitative videomicroscopy) to determine the impact of the transient silencing of CXCL2 on the growth kinetics of Hs683 cells. We used the Hs683 cell line to characterize the effects of CXCL2 silencing because, of the eight glioma cell lines examined, Hs683 expressed the greatest number of CXCLs and CXCL receptors (Table II and Fig. 2). We wanted to determine whether the transient depletion of a single CXCL, say CXCL2, in a glioma model expressing a large variety of CXCLs would actually impact the biological behavior of the glioma. As seen in Fig. 5C, transiently decreasing CXCL2 expression in Hs683 cells impaired global population growth and induced marked cytostatic effects. 'Transient' means that the CXCL2-specific siRNA approach we used decreased CXCL2 expression in Hs683 cells by over $50 \%$ from the fifth to the eighth day post-transfection (data not shown). However, even if transient, this short period of CXCL2 silencing was sufficient to delay the global growth rate of Hs683 cells by approximately 50\% (Fig. 5D). This delay in global Hs683 cell growth (Fig. 5D) reflects the cytostatic effects of the CXCL2specific siRNA, as morphologically illustrated in Fig. 5C.

\section{Discussion}

It is well known that $\mathrm{CXC}$ chemokines play a critical role in glioma cell biology, the roles of CXCL8 and the CXCL8 receptors and CXCL12/CXCR4 have been particularly well documented $(12,19)$. In human gliomas, CXCL8 is expressed and secreted at high levels and is proportional to GBM neovascularity and progression (12). The level of CXCL8 correlates with the histological grade in gliomas, and the highest expression is observed in the pseudopalisading cells around the areas of necrosis, suggesting that hypoxia/anoxia may stimulate the expression of CXCL8 (12). All of the GBM models that we used in the current study expressed CXCL8 mRNA (Fig. 2), while the level of synthesis and secretion of CXCL8 protein in standard culture conditions remained very low (Figs. 3 and 4). Therefore, it seems that hypoxic conditions are necessary to induce CXCL8 expression/secretions in glioma cells (12). The 


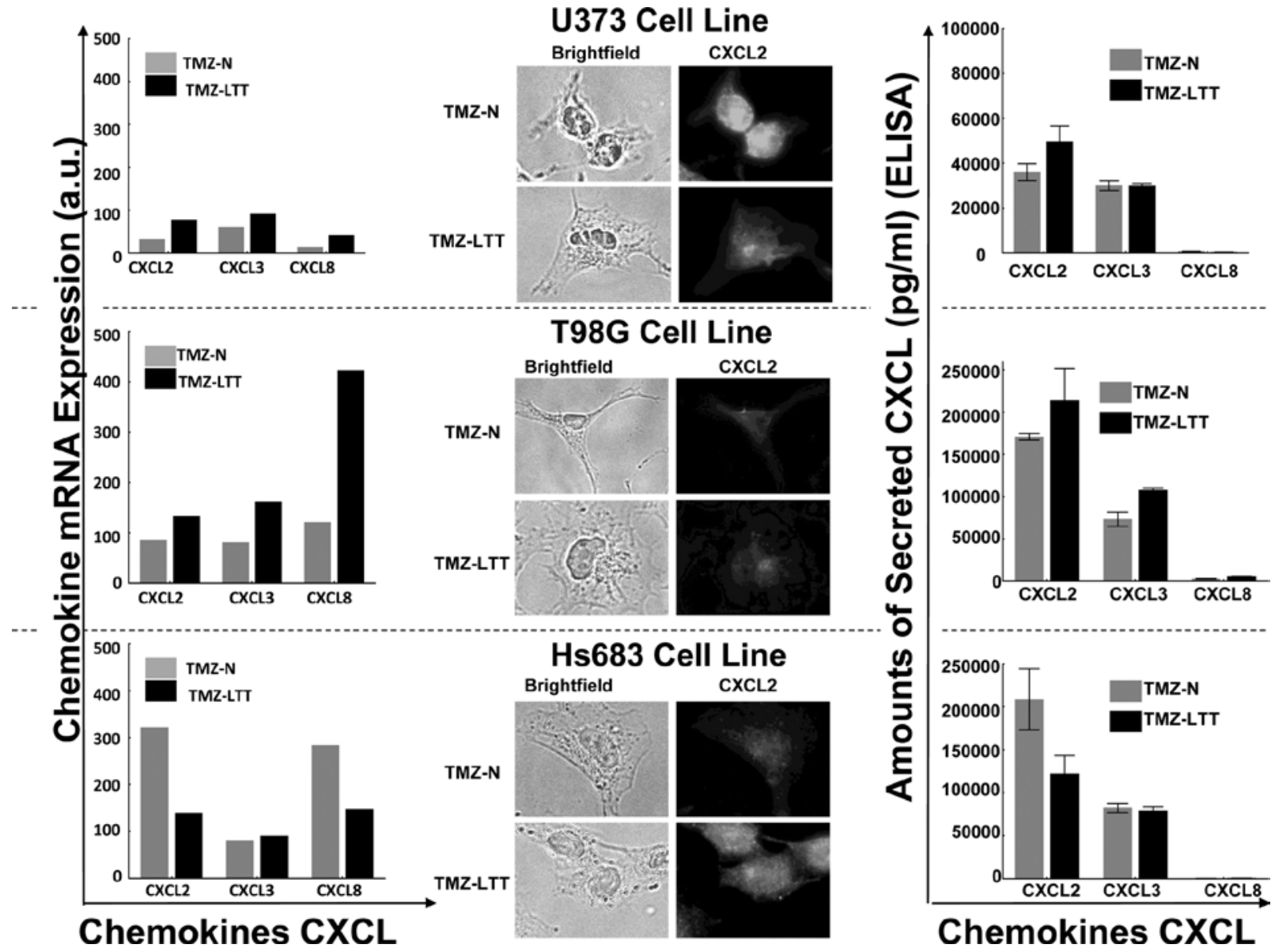

Figure 4. Impact of long-term temozolomide treatment on CXCL mRNA and protein expression and secretion. Three established glioma cell lines (Hs683, T98G and U373) were treated with increasing concentration of TMZ for months, as fully described in the Materials and methods. 'Naïve-TMZ' (TMZ-N) GBM cells, (i.e., GBM cells that had never been treated with TMZ) are represented by gray bars, while long-term TMZ-treated (TMZ-LTT) GBM cells are represented by black bars. The TMZ-N and TMZ-LTT GBM cells were submitted to a whole genome analysis (Affymetrix array Affymetrix Human Genome U133 set Plus 2.0), and we report the median values (arbitrary units) for the mRNA expression of CXCL2, CXCL3 and CXCL8, for the protein expression of CXCL2 (detected using immunofluorescence) and for the secretion of CXCL2, CXCL3 and CXCL8 (determined using ELISAs). The data are presented as means \pm SEM calculated from triplicates.

CXCL2 (and, to a lesser extent, the CXCL3) secretion level was elevated in vitro under standard culture conditions (Figs. 3 and 4).

CXCL12 and its cognate receptor CXCR4 have also been demonstrated to regulate malignant brain tumor growth and invasion (19,34-37). The eight GBM cell lines we used expressed CXCL12 mRNA, but only six of these lines expressed CXCR4 mRNA (Table II). These data are similar to the data published by Zagzag and colleagues (19) who detailed the expression of various combinations of CXCR4 and/or CXCL12 in the Scherer's structures of different GBMs. CXCL1 has also been demonstrated to confer increased tumorigenicity to glioma cells (15).

Based on the CXCL/CXCL receptor pattern observed in the present study, two GBM primocultures (GBM-P16 and GBM-P17) that expressed CXCL12 and CXCR4 mRNA failed to be tumorigenic in vivo under orthotopic grafting conditions in immunocompromised mice; all of the GBM cell lines, including GBM-P16 and GBM-P17, also expressed CXCL8 mRNA (Table II, Fig. 2). Seven of the eight GBM cell lines, including one of the two non-tumorigenic GBM cell lines (GBM-P16; Fig. 2D), expressed CXCL1 mRNA (Table II and Fig. 2). In contrast, the tumorigenic T98G model expressed only a low level of CXCL1 mRNA (Table II, Fig. 2). Therefore, it seems that CXCL1, CXCL8 and CXCL12/CXCR4 are important, but not sufficient, for the in vivo tumorigenicity (and thus the actual biological aggressiveness) of human glioma cell lines in immunocompromised mice. Our current data also suggest that a minimum level of CXCL2 and CXCL3 expression (Table II and Fig. 2) must be reached for these GBM cell lines to be tumorigenic in vivo (Fig. 2D).

Based on our data from the present study and from data published by other groups $(12,15,19,34-37)$, it seems that a minimal CXCL chemokine network involving CXCL1, CXCL2, CXCL3, CXCL8 and CXCL12/CXCR4 is necessary for GBM cells to be biologically aggressive in vivo, if tumorigenicity in immunocompromised mice is considered an endpoint of biological aggressiveness.

The data we presented implicate CXCL1, CXCL2 and CXCL3 in glioma cell growth and/or invasion but did not indicate a mechanism by which this occurs. In addition, the data from the present study show that long-term in vitro treatment of U373 and T98G astroglioma cells with TMZ leads to acquired in vivo $\mathrm{TMZ}$ resistance, a feature that is paralleled by increases in CXCL2, CXCL3 and CXCL8 expression and/ 
A

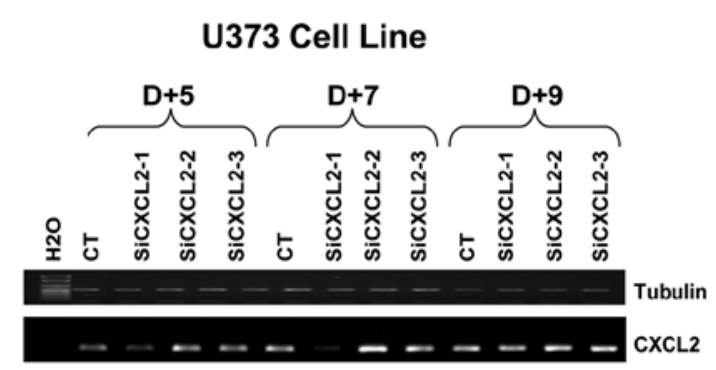

C

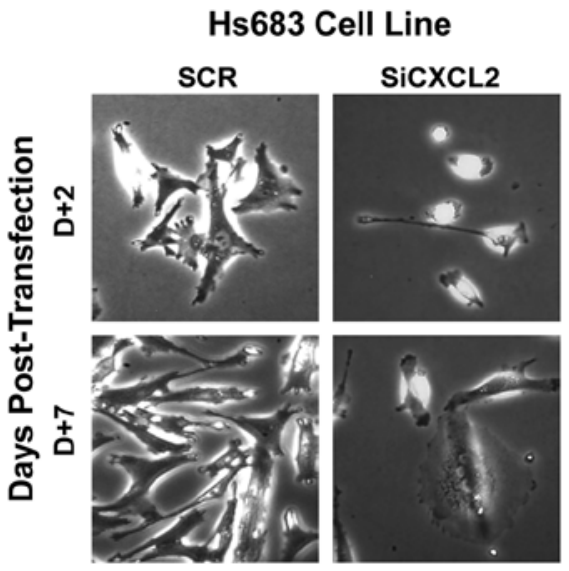

B
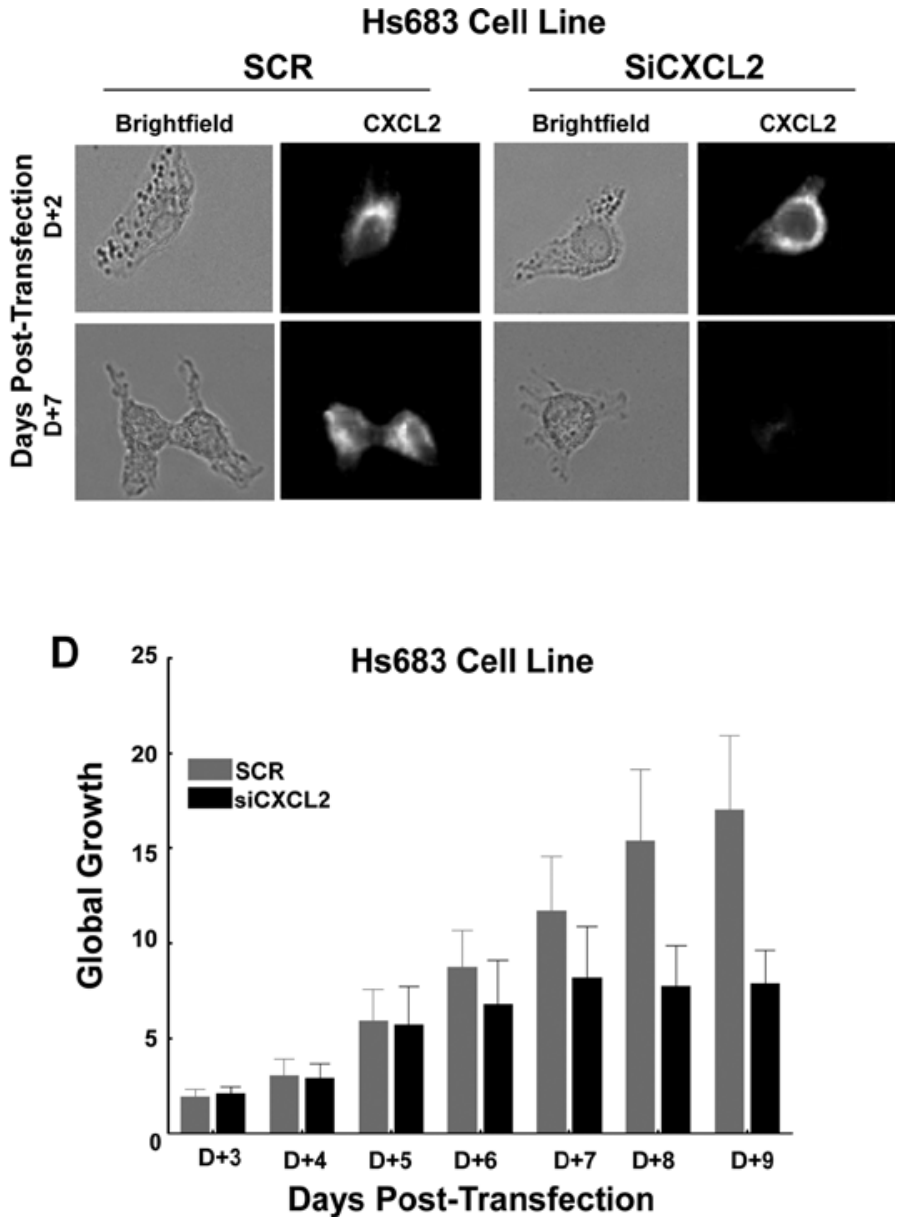

Figure 5. (A), Selection of the most efficient CXCL2 specific-siRNA in the U373 cell line using RT-PCR. The siRNA siCXCL2-1 silenced CXCL2 expression after 7 days. (B), Morphological illustration of the efficiency of a CXCL2-specific siRNA in decreasing CXCL2 expression in Hs683 cells 2 and 7 days posttransfection compared to the control siRNA (SCR). (C), Transfection of the CXCL2-specific siRNA (SiCXCL2) into Hs683 cells markedly impaired their morphology and proliferation compared to the transfection of a control siRNA (SCR). (D), The global growth ratio of Hs683 cells transfected with a control (SCR) or CXCL2-specific siRNA (siCXCL2) 3-9 days post-transfection was determined using a quantitative videomicroscopy approach (Materials and methods). The data are presented as means \pm SEM calculated from triplicates.

or secretion (Fig. 4). In contrast, the long-term in vitro treatment of Hs683 oligodendroglioma cells with TMZ leads to increased sensitivity in vivo to TMZ (27) and this feature is paralleled by decreases in CXCL2 and CXCL8 expression and/or secretion (Fig. 4).

When treating GBM cell lines in vitro with TMZ for short periods of time (one administration), we failed to detect decreased CXCL2, CXCL3 and CXCL8 secretion (Fig. 3). In contrast, when we repeatedly treated the GBM cells for one cycle of one administration a day for 5 days, we observed decreased CXCL2, CXCL3 and/or CXCL8 secretion in the GBM cells that displayed the highest TMZ sensitivity in vivo (i.e., T98G, Fig. 3, Table III).

Finally, even a transient decrease in the level of CXCL2 expression in Hs683 glioma cells, which display a broad and marked expression of CXCL chemokines and CXCL receptors (Table II and Fig. 2), was sufficient to impair HS683 cell growth, at least in vitro (Fig. 5). This suggests that CXCL2 plays a major role in the biological behavior of Hs683 glioma cells and that it does not seem to be fully redundant with other CXCLs.

Several studies have demonstrated a clear role for CXCL12 and its receptor CXCR4 in acquired resistance to various treat- ments, including radiotherapy and chemotherapy (35-38). However, to date, no such effects have been described for CXCL2 and CXCL3.

In conclusion, the data from the present study suggest potential roles for CXCL2 and CXCL3 (and also CXCL8) in the generation of certain levels of resistance to temozolomide in astroglioma but not in oligodendroglioma cells. We are in the process of setting up a prospective clinical study in which we aim to correlate the circulating level of CXCL2, CXCL3 and CXCL8 in GBM patients with their response to TMZ.

\section{Acknowledgements}

The present work was partially supported by grants awarded by the Fonds Yvonne Boël (Brussels, Belgium) and the Fonds National de la Recherche Scientifique (FNRS, Belgium). We would like to thank Dr Benjamin Haibe-Kains (Méthodes Algorithmiques en Probabilité, Faculty of Sciences, Université Libre de Bruxelles, Brussels, Belgium), Dr Gianluca Bontempi (Méthodes Algorithmiques en Probabilité, Faculty of Sciences, Université Libre de Bruxelles, Brussels, Belgium) and Dr Christine Deacestecker (Laboratoire de Toxicologie, Faculté 
de Pharmacie, Université Libre de Bruxelles, Brussels, Belgium) for helping us with the Affymetrix data analyses. We also warmly thank Thierry Gras for his technical assistance in in vitro experiments. R.K. is a Director of Research with the Fonds National de la Recherche Scientifique (FNRS, Belgium), and F.L. and C.L. a Clinical Research Fellow and a Postdoctoral Researcher with the FNRS, respectively.

\section{References}

1. Louis DN: Molecular pathology of malignant gliomas. Annu Rev Pathol 1: 97-117, 2006.

2. Lefranc F, Sadeghi N, Camby I, Metens T, Dewitte O and Kiss R: Present and potential future issues in glioblastoma treatment. Expert Rev Anticancer Ther 6: 719-732, 2006.

3. Ohgaki $\mathrm{H}$ and Kleihues P: Genetic pathways to primary and secondary glioblastoma. Am J Pathol 170: 1445-1453, 2007.

4. Lefranc F, Facchini V and Kiss R: Proautophagic drugs: a novel means to combat apoptosis-resistant cancers, with a special emphasis on glioblastomas. Oncologist 12: 1395-1403, 2007.

5. Stupp R, Hegi ME, Mason WP, van den Bent MJ, Taphoorn MJ, Janzer RC, Ludwin SK, Allgeier A, Fisher B, Belanger K, Hau P, Brandes AA, Gijtenbeek J, Marosi C, Vecht CJ, Mokhtari K, Wesseling P, Villa S, Eisenhauer E, Gorlia T, Weller M,Lacombe D, Cairncross JG and Mirimanoff RO; European Organisation for Research and Treatment of Cancer Brain Tumour and Radiation Oncology Groups; National Cancer Institute of Canada Clinical Trials Group: Effects of radiotherapy with concomitant and adjuvant temozolomide versus radiotherapy alone on survival in glioblastoma in a randomised phase III study: 5-years analysis of the EORTC-NCIC trial. Lancet Oncol 10: 434-435, 2009

6. Lefranc F, Brotchi J and Kiss R: Possible future issues in the treatment of glioblastomas: special emphasis on cell migration and the resistance of migrating glioblastoma cells to apoptosis. J Clin Oncol 23: 2411-2422, 2005.

7. Kanzawa T, Germano IM, Komata T, Ito H, Kondo Y and Kondo S: Role of autophagy in temozolomide-induced cytotoxicity for malignant glioma cells. Cell Death Differ 11: 448-457, 2004.

8. Katayama M, Kawaguchi T, Berger MS and Pieper RO: DNA damaging agent-induced autophagy produces a cytoprotective adenosine triphosphate surge in malignant glioma cells. Cell Death Differ 14: 548-558, 2007.

9. Roos WP, Batista LF, Naumann SC, Wick W, Weller M, Menck CF and Kaina B: Apoptosis in malignant glioma cells triggered by the temozolomide-induced DNA lesion $\mathrm{O}^{6}$-methylguanine. Oncogene 26: 186-197, 2007.

10. Kim JT, Kim JS, Ko KW, Kong DS, Kang CM, Kim MH, Son MJ, Song HS, Shin HJ, Lee DS, Eoh W and Nam DH: Metronomic treatment of temozolomide inhibits tumor cell growth through reduction of angiogenesis and augmentation of apoptosis in orthotopic models of gliomas. Oncol Rep 16: 33-39, 2006.

11. Mathieu V, De Nève N, Le Mercier M, Dewelle J, Gaussin JF, Dehoux M, Kiss R and Lefranc F: Combining bevacizumab with temozolomide increases the antitumor efficacy of temozolomide in a human glioblastoma orthotopic xenograft model. Neoplasia 10: 1383-1392, 2008.

12. Brat DJ, Bellail AC and van Meir EG: The role of interleukin-8 and its receptors in gliomagenesis and tumoral angiogenesis. Neuro-oncology 7: 122-133, 2005.

13. Balkwill F: Cancer and the chemokine network. Nat Rev Cancer 4: 540-550, 2004.

14. Vandercappellen J, van Damme J and Struyf S: The role of CXC chemokines and their receptors in cancer. Cancer Lett 267: 226-244, 2008

15. Zhou Y, Zhang J, Liu Q, Bell R, Muruve DA, Forsyth P, Arcellana-Panlilio M, Robbins S and Yong VW: The chemokine GROalpha (CXCL1) confers increased tumorigenicity to glioma cells. Carcinogenesis 26: 2058-2068, 2005.

16. Ehtesham M, Mapara KY, Stevenson CB and Thompson RC: CXCR4 mediates the proliferation of glioblastoma progenitor cells. Cancer Lett 274: 305-312, 2009.

17. Hoelzinger DB, Demuth T and Berens ME: Autocrine factors that sustain glioma invasion and paracrine biology in the brain microenvironment. J Natl Cancer Inst 99: 1583-1593, 2007.
18. Stevenson CB, Ehtesham M, McMillan KM, Valadez JG, Edgeworth ML, Price RR, Abel TW, Mapara KY and Thompson RC: CXCR4 expression is elevated in glioblastoma multiforme and correlates with an increase in intensity and extent of peritumoral T2-weighted magnetic resonance imaging signal abnormalities. Neurosurgery 63: 560-569, 2008.

19. Zagzag D, Esencay M, Mendez O, Yee H, Smirnova I, Huang Y, Chiriboga L, Lukyanov E, Liu M and Newcomb EW: Hypoxiaand vascular endothelial growth factor-induced stromal cell-derived factor-1alpha/CXCR4 expression in glioblastomas: one plausible explanation of Sherer's structures. Am J Pathol 173: 545-560, 2008.

20. Belot N, Rorive S, Doyen I, Lefranc F, Bruyneel E, Dedecker R, Micik S, Brotchi J, Decaestecker C, Salmon I, Kiss R and Camby I: Molecular characterization of cell-substratum attachments in human glial tumors relates to prognostic features. Glia 36: 375-390, 2001.

21. Branle F, Lefranc F, Camby I, Jeuken J, Geurts-Moespot A, Sprenger S, Sweep F, Kiss R and Salmon I: Evaluation of the efficiency of chemotherapy in in vivo orthotopic models of human glioma cells with and without $1 p / 19 q$ deletions and in C6 rat orthotopic allografts serving for the evaluation of surgery combined with chemotherapy. Cancer 95: 641-655, 2002.

22. Sivasankaran B, Degen M, Ghaffari A, Hegi ME, Hamou MF, Ionescu MC, Zweifel C, Tolnay M, Wasner M, Mergenthaler S, Miserez AR, Kiss R, Lino MM, Merlo A, Chiquet-Ehrismann R and Boulay JL: Tenascin-C is a novel RBPJkappa-induced target gene for Notch signaling in gliomas. Cancer Res 69: 458-465, 2009.

23. Le Mercier M, Mathieu V, Haibe-Kains B, Bontempi G, Mijatovic T, Decaestecker C, Kiss R and Lefranc F: Knocking down galectin-1 in human Hs683 glioblastoma cells impairs both angiogenesis through ORP150 depletion and endoplasmic reticulum stress responses. J Neuropathol Exp Neurol 67: 456-469, 2008.

24. Ikota H, Kinjo S, Yokoo H and Nakazato Y: Systematic immunohistochemical profiling of 378 brain tumors with 37 antibodies using tissue microarray technology. Acta Neuropathol 111: 475-482, 2006

25. Hubstenberger A, Labourdette G, Baudier J and Rousseau D: ATAD 3A and ATAD 3B are distal 1p-located genes differentially expressed in human glioma cell lines and present in vitro antioncogenic and chemoresistant properties. Exp Cell Res 314: 2870-2883, 2008

26. Boulay JL, Miserez AR, Zweifel C, Sivasankaran B, Kana V, Ghaffari A, Luyken C, Sabel M, Zerrouqi A, Wasner M, van Meir E, Tolnay M, Reifenberger G and Merlo A: Loss of NOTCH2 positively predicts survival in subgroups of human glial brain tumors. PLoS One 2: e576, 2007.

27. Lamoral-Theys D, Le Mercier M, Le Calvé B, Rynkowski MA, Bruyère C, Decaestecker C, Haibe-Kains B, Bontempi G, Dubois J, Lefranc $\mathrm{F}$ and Kiss R: Long-term temozolomide treatment induces marked amino metabolism modifications and an increase in TMZ sensitivity in Hs683 oligodendroglioma cells. Neoplasia 12: 69-79, 2010

28. Le Calvé B, Rynkowski M, Le Mercier M, Bruyère C, Lonez C, Gras T, Haibe-Kains B, Bontempi G, Decaestecker C, Ruyschaert JM, Kiss R and Lefranc F: Long-term in vitro treatment of human glioblastoma cells with temozolomide increases resistance in vivo through up-regulation of GLUT transporter and aldo-keto reductase enzyme AKR1C expression. Neoplasia 12: 727-739, 2010.

29. Berger W, Spiegl-Kreinecker S, Buchroithner J, Elbling L, Pirker C, Fischer J and Micksche M: Over-expression of the human major vault protein in astrocytic brain tumor cells. Int J Cancer 94: 377-382, 2001

30. Ruysschaert JM,El Ouahabi A and Willeaume V: A novel cationic amphiphile for transfection of mammalian cells. Biochem Biophys Res Commun 203: 1622-1628, 1994.

31. Elouahabi A, Flamand V, Ozkan S, Paulart F, Vandenbranden M, Goldman M and Ruysschaert JM: Free cationic liposomes inhibit the inflammatory response to cationic lipid-DNA complex injected intravenously and enhance its transfection efficiency. Mol Ther 7: 81-88, 2003.

32. De Hauwer C, Camby I, Darro F, Migeotte I, Decaestecker C, Verbeek C, Danguy A, Pasteels JL, Brotchi J, Salmon I, van Ham P and Kiss R: Gastrin inhibits motility, decreases cell death and increases cell proliferation in human glioblastoma cell lines. J Neurobiol 37: 373-382, 1998. 
33. Debeir O, Mégalizzi V, Warzée N, Kiss R and Decaestecker C: Videomicroscopic extraction of specific information on cell proliferation and migration in vitro. Exp Cell Res 314: 2985-2998, 2008.

34. Zhang J, Sarkar S and Yong VW: The chemokine stromal cell derived factor-1 (CXCL12) promotes glioma invasiveness through MT2-matrix metalloproteinase. Carcinogenesis 26: 2069-2077, 2005.

35. Woerner BM, Warrington NM, Kung AL, Perry A and Rubin JB: Widespread CXCR 4 activation in astrocytomas revealed by phosphor-CXCR4-specific antibodies. Cancer Res 65: 11392-11399, 2005 .
36. Ehtesham M, Winston JA, Kabos P and Thompson RC: CXCR4 expression mediates glioma cell invasiveness. Oncogene 25: 2801-2806, 2006.

37. Yang L, Jackson E, Woerner BM, Perry A, Piwnica-Worms D and Rubin JB: Blocking CXCR4-mediated cyclic AMP suppression inhibits brain tumor growth in vivo. Cancer Res 67: 651-658, 2007.

38. Kim DS, Kim JH, Lee JK, Choi SJ, Kim JS, Jeun SS, Oh W, Yang YS and Chang JW: Overexpression of CXC chemokine receptors is required for the superior glioma-tracking property of umbilical cord blood-derived mesenchymal stem cells. Stem Cells Dev 18: 511-519, 2009. 